\title{
Adaptação nutricional diante da doença celíaca desencadeada pela intolerância ao glúten
}

\section{Nutritional adaptation faced with celiac disease triggered by intolerance to gluten}

\author{
Francileuda Batista de Almeida \\ Graduada em Farmácia pela Faculdade Santa Maria. E-mail: fsmcz@hotmail.com \\ Symara Abrantes Albuquerque de Oliveira Cabral \\ Graduada em Enfermagem pela Universidade Federal de Campina Grande. E-mail: symara_abrantes@ hotmail.com \\ Maria Carmem Batista de Alencar \\ Graduada em Enfermagem pela Universidade Federal de Campina Grande. E-mail: symara_abrantes@ hotmail.com \\ Josefa Beatriz Gomes Sousa \\ Graduada em Farmácia pela Faculdade São Francisco da Paraíba - FASP, e-mail: bya_souzash@ hotmail.com \\ Bruno Albuquerque Gondim Cabral \\ Graduado em educação física pelo UNIPE. E-mail: brunoalbuquerquecz@hotmail.com
}

\begin{abstract}
Resumo: A intolerância ao glúten que desencadeia a doença celíaca DC tem analises e estudo a mais de dois séculos, glúten proteína presente nas farinhas, o doente celíaco tem como sintomas distúrbios gastrointestinais ente outros problemas de saúde decorrente de dietas a parti de alimentos que contem glúten. A partir de tais pressupostos, pretendeu-se com o trabalho de revisão, analisar a necessidade de adaptações nutricionais mediante a doença celíaca desencadeada pela intolerância ao glúten. Neste sentido, tem-se que os sintomas apesentam de formas típicas e atípicas. Fatores intrínsecos também contribuem para o problema tais com os imunológicos, genéticos e ambientais. Estudos comprovam que para melhor convivência com o problema o paciente celíaco deve obter todas as informações tanto do corpo clínico que lhe assiste quanto dos exames realizados como e o caso da biopsia do intestino. O tratamento se baseia em ingestão de dieta sem glúten, antes era difícil encontrar no mercado mais hoje já existem formulações sem glúten bolos goma xantana e biscoito de farrinha de palmeia real. Este trabalho descreve em formato de revisão bibliográfica este assunto.
\end{abstract}

Palavras-chaves: glúten, doença celíaca, intolerância.

Abstract: The intolerance to gluten that triggers the DC celiac disease has analysis and study more than two centuries, gluten protein found in flour, the patient celiac has the symptoms gastrointestinal being disorders other health problems due to diet the left of foods containing gluten. Based on these assumptions, it was intended with the revision work, examine the need for nutritional adaptations by celiac disease triggered by intolerance to gluten-. In this sense, it has to be apesentam symptoms of typical and atypical forms. Intrinsic factors also contribute to the problem with such immunological, genetic and environmental. Studies show that for better interaction with the patient celiac problem should get all the information from both the medical staff that assists you how much of examinations as is the case of bowel biopsy. The treatment is based on gluten-free diet intake before was difficult to find today in the already existing formulations gluten-free cakes xanthan gum and real palmeia binge biscuit market. The study presents literature review format this.

Keywords: gluten, celiac disease, intolerance. 


\section{INTRODUÇÃO}

Samuel Gee pesquisador inglês em 1888 descreve que a doença celíaca (DC) desencadeada pelo glúten, presente nas farinhas (trigo, cevada, aveia e centeio) que causava indigestão crônica encontrada em pessoas de todas as idades, especialmente em crianças com idades entre 1 e 5 anos (SDEPANIAN, 1999). E foi na Segunda Guerra Mundial que se associou os efeitos deletérios de certos tipos de cereais à (DC). Dicke, um pediatra holandês, observou que durante o período de racionamento de trigo, a incidência do "sprue celíaco" havia diminuído muito. Posteriormente, quando os aviões suecos trouxeram pão para a Holanda, as crianças com doença celíaca voltaram rapidamente a apresentar sintomas, confirmando a importância do trigo na gênese da doença (SDEPANIAN, 1999).

A DC é uma intolerância permanente ao glúten, caracterizada por atrofia total ou subtotal da mucosa do intestino delgado proximal e consequente má absorção de alimentos, em indivíduos geneticamente susceptíveis (ANTUNES H,2006). Para que ocorra a expressão da DC, além do uso do glúten na dieta, é também necessária a presença de outros fatores, tais como: genéticos, imunológicos e ambientais (ANTUNES H,2006). Inúmeros estudos demonstraram anormalidades imunológicas características da doença como a presença de anticorpos circulantes e de linfócitos com receptores gama/delta presentes em grande número a nível intraepitelial da mucosa intestinal (SDEPANIAN, 1999).

Alguns estudos realizados na Grã-Bretanha e Irlanda, observaram decréscimo da incidência da DC quando o glúten era introduzido tardiamente na dieta. Porém, estudo subsequente demonstrou que a introdução tardia do glúten na dieta retarda o início da sintomatologia, com redução das formas típicas e proporcional aumento das formas atípicas da doença tanto na criança, quanto no indivíduo adulto. Recentemente, estudos de rastreamento têm demonstrado alta prevalência da doença em crianças e adultos aparentemente saudáveis. Assim, é possível postular-se que, anteriormente, a maioria dos casos não era diagnosticada, provavelmente devido à diminuição dos casos típicos (ANTUNES H., 2006).

A definição das áreas de risco baseia-se na história das migrações dos povos ancestrais e no facto de a doença resultar de fatores genéticos e ambientais. Assim, a DC é comum na Europa, América, norte de África, sudeste asiático e Austrália, onde se associam a presença dos haplotipos implicados e o elevado consumo de glúten (NOBRE S. R., 2007).

\section{METODOLOGIA}

Diante da relevância do tema, buscando analisar a necessidade de adequações nutricionais perante doença celíaca desencadeada por intolerância ao glúten, fez-se necessário uma análise bibliográfica acerca do tema.

Para tanto, realizou-se uma busca sistemática de artigos científicos na base de dados da Biblioteca Virtual em Saúde (BVS), através dos termos interligados: glúten, doença celíaca, intolerância.

\section{REVISÃO BIBLIOGRÁFICA}

O glúten é uma proteína que está presente no trigo, centeio, cevada e aveia. Os cereais que pertencem à família Gramineae podem ser divididos em quatro subfamílias, a saber: Bambusoidea, Pooideae, Panicoideae e Chloridiodeae. A subfamília Pooideae compreende dois subgrupos: Triticeae que contém a maioria dos cereais: trigo (triticum), centeio (secale), e cevada (hordeum); e Aveneaeque contém a aveia (avena). De acordo com Antunes (2006). A avaliação da IgA total conjuntamente com a determinação dos anticorpos antitransglutaminase tecidular é aparentemente o melhor método de rastreio, porque é menos dispendioso e devido à utilização do método de ELISA, e por isso, mais fácil de estar disponível em todo o país.

Estudo realizado por Galvão (2004), diante do quadro clínico, os pacientes foram alocados em dois subgrupos: típica e atípica. Considerados forma típica aqueles que referiram pelo menos dois dos seguintes sinais/ sintomas: diarreia, perda de peso e distensão abdominal. A demais forma atípica. Com registro da idade pacientes quando diagnosticado. Estado nutricional avaliado no momento do diagnóstico. Tempo de doença decorrido entre o início dos sintomas e o diagnóstico da DC. Dessa forma, através de tal trabalho concluiu-se que não houve diferenças em relação à forma de apresentação clínica da DC, bem como na idade de início de sintomas, tempo entre sintomas e diagnóstico e estado nutricional dos pacientes.

Com relação a apresentação clínica na infância, a DC apresenta-se tipicamente entre os 6 e os 24 meses de idade, após a introdução dos cereais na dieta, com instalação gradual de diarreia, distensão abdominal, anorexia, atraso de crescimento, atrofia muscular, hipotonia, irritabilidade, vômitos até os 9 meses e dor abdominal (NOBRE; SILVA; CABRAL, 2007).

Nas crianças mais velhas e adolescentes, a doença pode ser pautada por atraso no desenvolvimento estato-ponderal e pubertário, raquitismo, diarreia, anemia recorrente ou desempenho escolar deficiente no adulto alterou-se substancialmente. $\mathrm{O}$ atingimento do intestino delgado proximal resulta em deplecção de ferro, ácido fólico, cálcio e vitaminas lipo-solúveis, ao passo que o envolvimento ileal, nos casos de doença extensa, condiciona défice de vitamina B12 (NOBRE; SILVA; CABRAL, 2007).

No tocante as suas formas clínicas, a doença celíaca apresenta na forma típica a tríade clássica, consistindo em esteatorreia, meteorismo abdominal e emagrecimento, já não é a principal forma de revelação da DC. Na verdade, até $30 \%$ dos doentes celíacos apresentam aumento do índice de massa corporal no momento do diagnóstico (NOBRE; SILVA; CABRAL, 2007).

Nas formas atípicas a sintomatologia gastrintestinal é frequentemente ligeira e inespecífica (obstipação isolada ou alternância com diarreia), mimetizando um quadro de colopatia funcional. Estima-se que a prevalência de DC em doentes com síndroma do intestino irritável seja de 4,6\%. Astenia e mal-estar geral são queixas relativamente frequentes e anorexia (NOBRE; SILVA; CABRAL, 2007). 
Nas formas extra-intestinais a DC pode apresentar-se como uma anemia ferropénica inexplicada, sendo responsável por até $5 \%$ destes casos. Recomenda-se a realização sistemática de biópsias duodenais no decurso de uma endoscopia digestiva alta efectuada neste âmbito. (NOBRE; SILVA; CABRAL, 2007). A osteopénia é a complicação mais frequente da DC, constituindo por vezes o modo de apresentação. Decorre da má-absorção de vitamina $\mathrm{D}$ e cálcio, e diminuição do seu aporte (em situações de intolerância à lactose).

Outros fatores, designadamente o sexo feminino, desnutrição e redução da atividade física. Lombalgia arrastada, que apenas responde parcialmente à dieta sem glúten. Pode evoluir para osteoporose. Deve ser sempre realizada uma densitometria óssea no momento do diagnóstico, para avaliar a gravidade da perda de massa óssea e instituir a terapêutica adequada. $\mathrm{O}$ envolvimento das articulações periféricas, mais raro, decorre com oligoartralgias ou oligo-artrites ser o negativas. O défice de cálcio e magnésio pode resultar em parestesias, cãibras musculares ou mesmo tetânica (NOBRE; SILVA; CABRAL, 2007).

Neste sentido, tem-se que as doenças e síndromas associadas à DC incluem: Patologia cutâneo-mucosa, Patologia hepatobiliar e pancreática, Endocrinopatias, Défices imunitário, Síndromas malformativas, Patologia neurológica e psiquiátrica (NOBRE; SILVA; CABRAL, 2007)

Formas silenciosas que ocorre com indivíduos assintomáticos, identificados pela existência de fatores de risco, que apresentam atrofia vilositária nas biópsias duodenais. Estão expostos às complicações habituais da doença e devem manter uma dieta sem glúten (NOBRE; SILVA; CABRAL, 2007).

Formas latentes de evolução são variáveis e a instituição de uma dieta restritiva é discutível. Englobam sob esta designação os sujeitos assintomáticos com anticorpos circulantes e presença de linfocitose intraepitelial nas biópsias do duodeno, que podem desenvolver DC clinicamente evidente após exposição prolongada ao glúten (NOBRE; SILVA; CABRAL, 2007).

No tocante as complicações da DC tem-se: Hipoesplenismo e Cavitação dos Gânglios do Mesentério, Jejunite Ulcerativa. Complicações Malignas: As neoplasias são a complicação mais grave da DC do foro otorrinolaringológico e do esófago. Os carcinomas epidermóides, adenocarcinoma do intestino delgado, linfoma de células $\mathrm{T}$, anomalias citogenéticas (NOBRE; SILVA; CABRAL, 2007).

Alta prevalência de doença celíaca em pacientes com síndrome de Down tem sido descrita em vários países. .( Oliveira N. P., Fiedler P. T., Reason I. T. M., 2005). Estudo mostram alta prevalência $(5,6 \%)$ de doença celíaca confirmada em crianças e adolescentes com síndrome de Down também no Brasil especificamente na região sul do. (Oliveira N. P., Fiedler P. T., Reason I. T. M., 2005). Pode esta relacionada a marcadores genéticos comuns compartilhados. Já foi demonstrado que portadores da SD com DC apresentam DC característica associada aos antígenos leucocitários humanos de altorisco (HLA) DR3 e alelos DQ221. Além disso, as desordens genéticas causadas pelo desequilíbrio cromossômico podem estar relacionadas a uma maior expressão da DC em pacientes com SD (OLIVEIRA; FIEDLER; REASON, 2005)

Com relação a avaliação, achados da avaliação endoscópica e histológica demonstram que a DC afeta o intestino delgado proximal, a biópsias devem ser efetuadas na segunda ou terceira porções do duodeno, por forma a evitar a distorção arquitetural produzida pelas glândulas de Brünner e a duodenite péptica (NOBRE; SILVA; CABRAL, 2007).

O tratamento está instituído de uma dieta sem glúten, indefinidamente, é a única terapêutica eficaz da DC não complicada, conduzindo, em regra, a melhoria sintomática em algumas semanas. No entanto, a restrição absoluta de glúten é difícil ou mesmo impossível de manter, dada a presença de quantidades residuais nos alimentos disponíveis no mercado consideram que o limite de glútenresidual pode ser estabelecido em $100 \mathrm{mg} / \mathrm{Kg}$ de produto. Para uma ingestão diária de $300 \mathrm{~g}$ de farinha, o nível de $100 \mathrm{mg} / \mathrm{Kg}$ resulta em $30 \mathrm{mg}$ de glúten, o que se mostrou seguro na prática clínica (NOBRE; SILVA; CABRAL, 2007).

Levando em consideração a prevenção de complicações não-malignas e especialmente aquelas com risco de malignidade, a obediência à dieta e do conhecimento da DC e de seu tratamento possibilitou confirmar a possível relação positiva entre ambas, quanto maior o conhecimento da DC e de seu tratamento, maior o grau de obediência à dieta isenta de glúten (SDEPANIAN, 2001).

Um achado interessante e importante deste estudo foi que os pacientes que realizaram pelo menos uma biopsia de intestino delgado são mais obedientes à dieta, especialmente não ingerindo frequentemente $\mathrm{o}$ glúten (SDEPANIAN, 2001).

Assim, os conhecimentos transmitidos pelos médicos, nutricionistas, assim como, associações de celíacos constituem fatores importantes para aumentar o número de pacientes obedientes à dieta, garantindo desta forma o sucesso do tratamento (SDEPANIAN, 2001).

Uma oposição para dieta sem glúten. Cientistas de alimentos tentam buscar ingredientes que apresentem características funcionais semelhantes ao glúten, sem prejuízo à qualidade dos alimentos e à saúde dos consumidores (PREICHARDT L, 2009).

Estudos revelam que a adição de xantana melhorou as características sensoriais dos bolos sem glúten formulados com farinha de arroz e milho (PREICHARD, 2009). O retardo do envelhecimento, a menor formação de migalhas e a maior sensação de umidade na boca se destacaram nos bolos adicionados desta goma. Portanto, a goma xantana teve efeito benéfico sobre as características sensoriais dos bolos sem glúten podendo ser utilizada de maneira satisfatória na elaboração desses produtos, melhorando expressivamente sua qualidade sensorial (PREICHARDT, 2009).

Nos biscoitos sem glúten a presença de farinha de palmeira-real melhorou a composição química destes, devido ao maior conteúdo de fibra alimentar e minerais e redução dos valores de carboidratos e energia (SIMAS, 2008)

A adição de farinha de palmeira-real influenciou nas características físico-químicas de massas e biscoitos sem glúten. A análise do perfil de textura revelou que a 
adição de farinha de palmeira-real aumentou a força de fratura e firmeza de biscoitos, além de afetar as características de textura de massas contendo diferentes níveis de farinha de palmeira-real. Esses resultados revelaram que a farinha de palmeira-real pode ser utilizada para suplementação de biscoitos sem glúten, melhorando a disponibilidade de ingredientes funcionais aos consumidores celíacos (SIMAS, 2008).

\section{CONSIDERAÇÕES FINAIS}

A introdução de alimentos que contem glúten ao longo do tempo na vida de um portador da doença celíaca desencadeia formas atípicas da doença ao longo do tempo. O Brasil já tem dados sobre os portadores de Síndrome de Down que apresenta a doença celíaca DC. O presente estudo mostra que a doença celíaca um problema de saúde antigo e que ao longo dos anos a dificuldades para se conviver com esta doença está se tornando adaptável, fazendo com que o portador desta doença tenha todas as informações que possa fazer com que ele aceite faze uso de uma dieta isenta de glúten de forma simples sem lhe causas quais quer transtorno.

O paciente celíaco consegue conviver normalmente com este problema de saúde sem sofrimento utilizando dietas sem glúten e ou alimentos que tenha a substituição do glúten por outra proteína como e o caso do bolo de goma xantana e o biscoito de palmeira real.

Assim como vem evoluindo a pesquisa sugeri que novas formulações sejam feitas para produção de alimentos que venham a ajudar os portadores de doença celíaca a ter mais opções em sua dieta. Já que o único tratamento e se abster de alimentos que contem glúten.

\section{REFERÊNCIAS BIBLIOGRÁFICAS}

SDEPANIAN V.L.; MORAIS M.B.; e NETO F.U. A evolução dos conhecimentos desde sua centenária descrição original até os dias atuais. Arq. Gastroenterol. v.36 n.4 São Paulo out./dez. 1999.

ANTUNES H. et al . Primeira determinação de prevalência de doença celíaca numa população portuguesa. Acta Med Port 2006; 19: 115-120.
NOBRE S. R.; SILVA T. ;CABRAL J.E. P. Doença celíaca revisitada. GE - J Port Gastrenterol 2007; 14: 184193

BROWN I, MINO-KENUDSON M, DESHPANDE V, LAUWERS GY. Intraepithelial lymphocytosisin architecturally preserved proximal small intestinal mucosa: An increasing diagnosticproblem with a wide differential diagnosis. Arch Pathol Lab Med 2006; 130: 1020-5.

GALVÃO L. C., BRANDÃO J. M. M.,FERNANDES M. I. M., CAMPOS A. D. Apresentação clínica de doença celíaca em crianças durante dois períodos, em serviço universitário especializado. Arq Gastroenterol v. 41 - no.4 - out./dez. 2004.

OLIVEIRA N. P., FIEDLER P. T., REASON I. T. M. Doença celíaca em crianças e adolescentes com síndrome de Down. Jornal de Pediatria - Vol. 81, No.5, 2005.

SDEPANIAN V. L., MORAIS M. B., NETO U. F. DOENÇA CELÍACA: avaliação da obediência à dieta isenta de glúten e do conhecimento da doença pelos pacientes cadastrados na Associação dos Celíacos do Brasil (ACELBRA). Arq. Gastroenterol. v.38 n.4 São Paulo out./dez. 2001.

SIMAS K. N. Resíduo do processamento da palmeira-real (archontophoenix Alexandrae) orgânica: caracterização físico-química, Aplicação em biscoitos fibrosos sem glúten e avaliação Sensorial pelo consumidor celíaco. Universidade Federal de Santa Catarina Centro de ciências Agrárias Departamento de Ciência e Tecnologia de Alimentos Programa de pós-graduação em ciência dos alimentos. Florianópolis, março de 2008.

PREICHARDT L. D. , VENDRUSCOLO C. T., GULARTE M. A., MOREIRA A. DA S. Efeito da goma xantana nas características sensoriais de bolos sem glúten. Revista Brasileira de Tecnologia Agroindustrial v. 03, n. 01: p. 70-76, 2009. 
